\title{
Continuous field soil moisture content mapping by means of apparent electrical conductivity $\left(E C_{\mathrm{a}}\right)$ measurement
}

\author{
Viliam Nagy ${ }^{1}$, Gábor Milics ${ }^{* 2}$, Norbert Smuk $^{2}$, Attila József Kovács ${ }^{2}$, István Balla ${ }^{3}$, Márton Jolánkai ${ }^{3}$, \\ József Deákvári ${ }^{4}$, Kornél D. Szalay ${ }^{4}$, László Fenyvesi ${ }^{4}$, Vlasta Štekauerová ${ }^{\dagger 1}$, Zoltán Wilhelm ${ }^{5}$, \\ Kálmán Rajkai ${ }^{6}$, Tamás Németh ${ }^{6}$, Miklós Neményi ${ }^{2}$ \\ ${ }^{1}$ Institute of Hydrology, Slovak Academy of Sciences, Račianska 75, 831 02, Bratislava, Slovakia. \\ ${ }^{2}$ Institute of Biosystems Engineering, University of West Hungary, Vár 2, H-9200 Mosonmagyaróvár, Hungary. \\ ${ }^{3}$ Institute of Crop Production, Szent István University, Páter Károly u. 1, H-2100 Gödöllő, Hungary. \\ ${ }_{5}^{4}$ Hungarian Institute of Agricultural Engineering, H-2100, Tessedik Sámuel u. 4, H-2100 Gödöllő, Hungary. \\ ${ }^{5}$ Department of General and Applied Environmental Geography, Institute of Geography, University of Pécs, Ifjúság u. 6, H-7624 Pécs, \\ Hungary. \\ ${ }^{6}$ Centre for Agricultural Research, Hungarian Academy of Sciences, Institute for Soil Science and Agricultural Chemistry, Hermann Ottó \\ u. 15, H-1022 Budapest, Hungary. \\ ${ }^{*}$ Corresponding author. Tel.: +3696566 635. Fax: +3696566641. E-mail: milics@mtk.nyme.hu \\ ${ }^{\dagger}$ Deceased
}

\begin{abstract}
A soil moisture content map is important for providing information about the distribution of moisture in a given area. Moisture content directly influences agricultural yield thus it is crucial to have accurate and reliable information about moisture distribution and content in the field. Since soil is a porous medium modified generalized Archie's equation provides the basic formula to calculate moisture content data based on measured $E C_{\mathrm{a}}$. In this study we aimed to find a more accurate and cost effective method for measuring moisture content than manual field sampling. Locations of 25 sampling points were chosen from our research field as a reference. We assumed that soil moisture content could be calculated by measuring apparent electrical conductivity $\left(E C_{\mathrm{a}}\right)$ using the Veris-3100 on-the-go soil mapping tool. Statistical analysis was carried out on the $10.791 E C_{\mathrm{a}}$ raw data in order to filter the outliers. The applied statistical method was \pm 1.5 interquartile (IRQ) distance approach. The visualization of soil moisture distribution within the experimental field was carried out by means of ArcGIS/ArcMAP using the inverse distance weighting interpolation method. In the investigated 25 sampling points, coefficient of determination between calculated volumetric moisture content data and measured $E C_{a}$ was $\mathrm{R}^{2}=0.87$. According to our results, volumetric moisture content can be mapped by applying $E C_{\mathrm{a}}$ measurements in these particular soil types.
\end{abstract}

Keywords: Moisture content mapping; Apparent electrical conductivity; Data preparation and interpolation; Precision agriculture.

\section{INTRODUCTION}

Mapping the distribution of soil moisture content is a crucial source for precision agriculture. The most reliable method is sampling and laboratory analysis; however this is time consuming and labor intensive (Sharma et al., 1997). Other techniques to measure moisture content in real time such as TDR sensors present difficulties (Doležal et al., 2012). Capacitance probe based measurements also require site-specific calibration equations rather than the manufacturer's default equation (Paraskevas et al., 2012).

In most cases manual sampling and laboratory analysis does not provide enough information for mapping field differences. On-line instruments measuring soil properties are going to be the next generation of tools for researchers dealing with precision agriculture. Apparent electrical conductivity $\left(E C_{\mathrm{a}}\right)$ measurements provide a wealth of data in a relatively short time period. Relation between $E C_{\mathrm{a}}$ and salinity (Corwin and Rhoades, 1982, 1984; Halvorson and Rhoades, 1976), moisture content (Fitterman and Stewart, 1986; Kaffka et al., 2005), soil structure (Brevik and Fenton, 2002; Rhoades et al., 1999) and other factors (Cook et al., 1992; Ellsbury et al., 1999) were published earlier.

Apparent electrical conductivity measurements were carried out previously in our experimental field in connection with precision agriculture (Milics, 2013). Correlation between clay content and $E C_{\mathrm{a}}$ was found strong $\left(\mathrm{R}^{2}=0.93\right)$. As soil is a porous medium, several measurement methods and functions have been developed and proposed for predicting its apparent electrical conductivity. Corwin and Lesch (2003) published a study on the theoretical background of $E C_{\mathrm{a}}$ measurements. The physical appearance of VERIS mobile $E C_{\mathrm{a}}$ measurement equipment can be found in Corwin and Lesch (2003). The measuring background of the equipment is based on the Wenner array four electrode method (Corwin and Lesch, 2005). Texture, conductivity of pore solution and moisture content highly influences apparent electrical conductivity $\left(E C_{\mathrm{a}}\right)$. Shah and Shing (2005) adjusted Archie's law (Eq. (1)), which relates apparent electrical conductivity and volumetric moisture content as:

$$
E C_{a}=c \cdot E C_{w} \cdot \theta^{m}
$$

where $E C_{\mathrm{a}}$ is apparent electrical conductivity $(\mathrm{mS} / \mathrm{m})$ of the soil, $E C_{\mathrm{w}}$ is electrical conductivity of pore solution $(\mathrm{mS} / \mathrm{m}), \theta$ is volumetric moisture content of the soil (\%), $c, m$ are constants $(-)$.

The future of precision agriculture and natural resource management rests on the reliability, reproducibility, and understanding of the technological developments upon which it is 
based (Kravchenko and Bullock, 2000; Milne, 1991; Williams and Hoey, 1987). The purpose of our research was to investigate the relationship between moisture content and $E C_{\mathrm{a}}$ to find a faster, easier, more accurate and cost effective way of moisture content mapping.

\section{MATERIALS AND METHODS Study field}

Measurements were carried out in the experimental study field of the Institute of Biosystems Engineering, Faculty of Agricultural and Food Sciences, University of West Hungary near Mosonmagyaróvár, Hungary. The experimental study field is situated on 23.52 hectares of the agricultural land (N4754'20.00"; E17 $\left.15^{\prime} 10.00^{\prime \prime}\right)$ on which precision agriculture has been applied since 2001 (Fig. 1).

The 23.52 ha area is an agricultural alluvial plain of the Leitha River. The field cannot be characterized by one typical soil profile, as a buried riverbed (former Leitha) crosses it. The humus content in the upper $0.2 \mathrm{~m}$ layer is between $1.4-2.8 \%$ in this alluvial soil. Depending on the location loam and silty loam appears on the field. The elevation differences in the area are slightly more than $2 \mathrm{~m}$, decreasing from the East side towards the North-West corner of the field. Measurements were carried out on 14th November, 2012.

\section{Moisture content in the soil}

Moisture content was determined by means of gravimetric method. Based on previous measurements (Milics et al., 2012) sampling sites were selected on a grid consisting of 25 points spaced $50 \mathrm{~m} \times 50 \mathrm{~m}$. (Fig. 1). Sample sites were identified on the field be means of handheld Garmin GPS instrument. Six undisturbed soil samples (50 $\mathrm{mm}$ in height) were taken consec- utively from each sampling site. The sampling depth was thus $0.3 \mathrm{~m}$. Altogether 150 samples were collected. Soil samples were dried to a constant weight ( $>24 \mathrm{hr}$ ) in the oven at temperature $105^{\circ} \mathrm{C}$. After drying, gravimetric and volumetric moisture content was determined. Volumetric moisture contents $(\theta)$ were calculated from the known volume $\left(100 \mathrm{~cm}^{3}\right)$ of the core soil sampling rings.

\section{Apparent electrical conductivity $\left(E C_{\mathrm{a}}\right)($ Veris-3100)}

The soil $E C_{a}$ was measured by Veris-3100 (Salina, KS, USA) instrument. The measurement is based on the following expression:

$$
G=E C_{\mathrm{a}} \frac{A}{l},
$$

where $G$ is electrical conductance (S), $A$ is cross-sectional area of the electrical conductor $\left(\mathrm{m}^{2}\right), l$ is length of the electrical conductor (m). Apparent electrical conductivity is a characteristic of the material; it is reciprocal to the specific resistance, and it is temperature dependent.

The most important parts of the Veris-3100 meter are the measuring disks (6 pcs) with $\varnothing 430 \mathrm{~mm}$ diameters, which are electrically insulated from other units (Fig. 2). The disks are arranged symmetrically. The device measures the apparent electrical conductivity of the soil in depths of $0-0.3 \mathrm{~m}$ and 0 $0.9 \mathrm{~m}$ at the same time. In this study data from the depth of 0 $0.3 \mathrm{~m}$ was used, as the reference soil samples were also collected from this depth. In order to locate the measurement points, a GPS receiver is needed, which - for accuracy - operates in differential mode. The Veris-3100 meter stores the measured data once every second. After the measuring process is over, the recorded data can be saved.

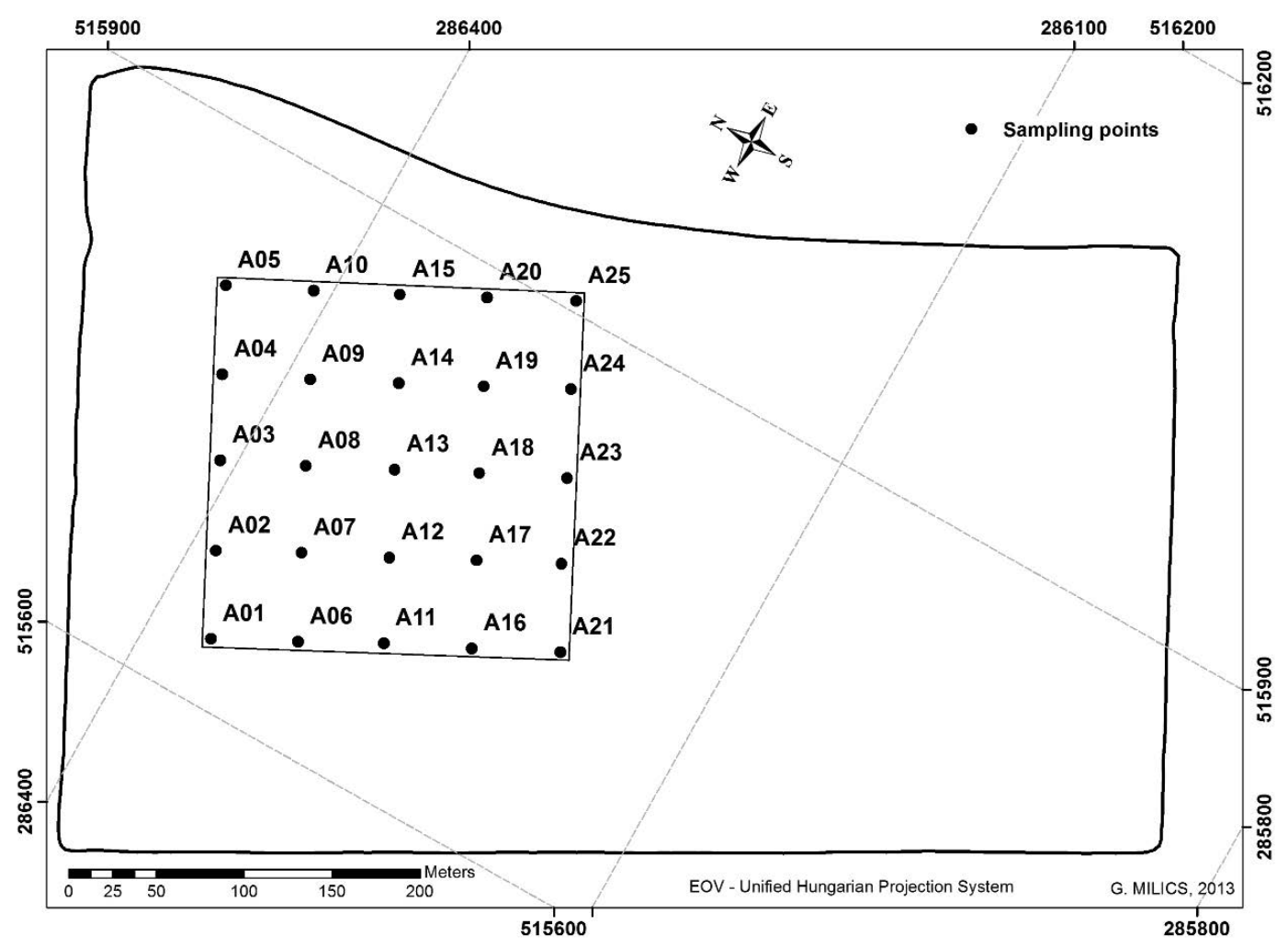

Fig. 1. Spatial distribution of sampling points for gravimetric soil moisture content measurements on the investigated field. 


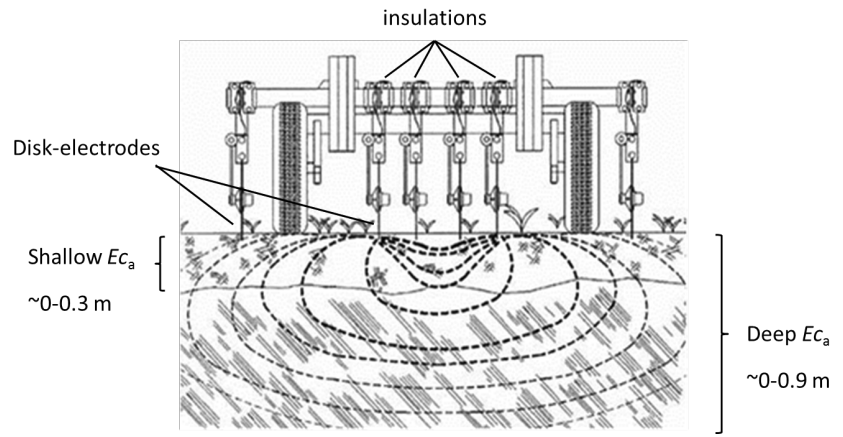

Fig. 2. Functional principle and conformation of Veris-3100 soil apparent electrical conductivity $\left(E C_{\mathrm{a}}\right)$ instrument. (Source: Veris Technologies - www.veristech.com)

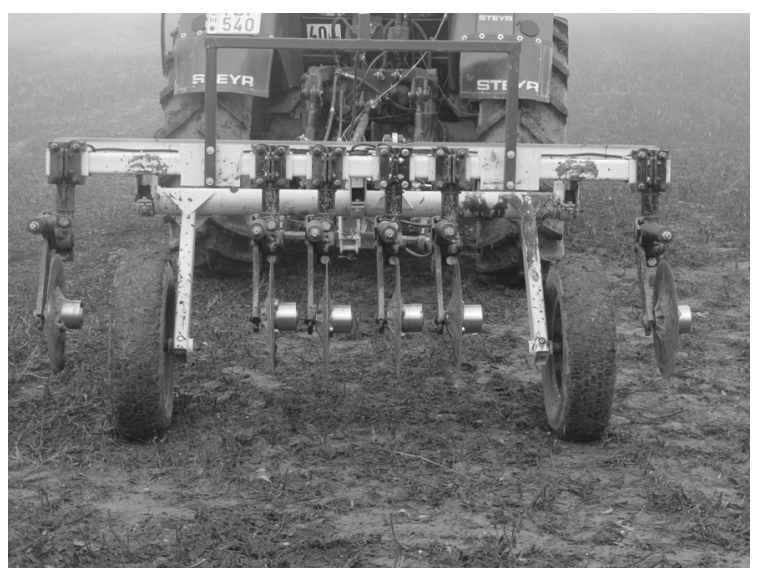

a)

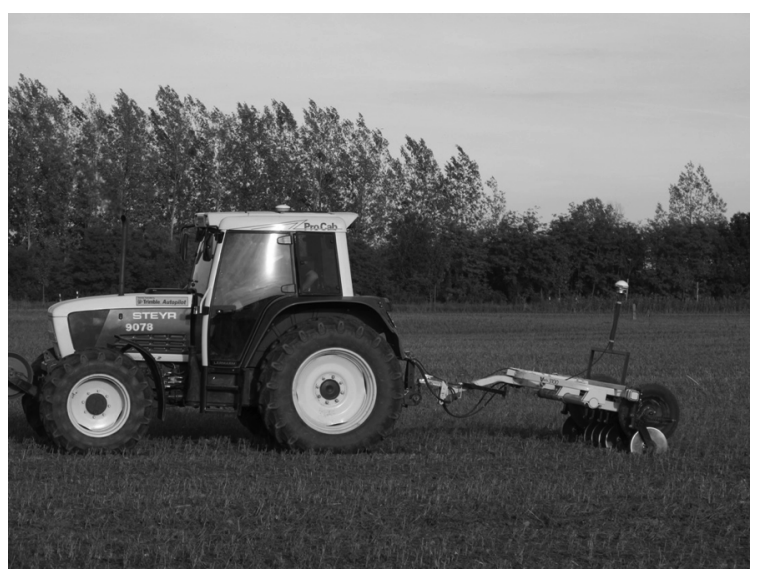

b)

Fig. 3. VERIS-3100 instrument in the study field: arrangement of heavy-duty coulter-electrodes (a); pulling the equipment during measurements (b).

We pulled the Veris-3100 device with a tractor (Fig. 3a and b). During measuring electrical conductivity we used a Trimble AgGPS (Sunnyvale, CA, USA) 114 row marker, which provided the GPS coordinates to the Veris-3100 meter. This instrument was used as a row marker at the same time. Measurements were carried out at a tractor speed level between $18-20 \mathrm{~km} / \mathrm{h}$. Therefore measurement of the apparent electrical conductivity of the recorded field happened approximately every 5 meters. The adjusted row distance was $5 \mathrm{~m}$, consequently the measured data was registered approximately in a $5 \times 5 \mathrm{~m}$ grid.
Applying the adjusted Archie's law (Eq. (1)) determined by Shah and Shing (2005) volumetric moisture content was calculated by the following equation:

$\theta=\left(\frac{E C_{a}}{d}\right)^{\left(\frac{1}{m}\right)}$

where $d$ is parameter containing electrical conductivity of pore solution $(\mathrm{mS} / \mathrm{m})$, which in our case was considered as constant.

\section{Statistical analysis and filtering of the collected $E C_{\mathrm{a}}$ data}

In order to define outliers, all tests require normal distribution. Therefore, histograms for $E C_{\mathrm{a}}$ measured data were created. The histogram showed non-normal distribution, therefore in order to statistically prove the normality or non-normality of the datasets Anderson-Darling test (Anderson and Darling, 1954) and Kolmogorov-Smirnov (K-S) test (Justel et al., 1997) were used. P-value was smaller than the critical value; therefore further statistical analysis without transforming the data was not applicable. In order to apply the filtering methods for the dataset, log-normal distribution tests were investigated. Prior the analysis false measurement data such as ' 0 ' and negative values were removed from the dataset and natural logarithm of the remaining values were calculated. Out of the 10.791 data 10.748 data was used. Calculations and mapping was based on the data which have been filtered.

\section{Statistical analysis of moisture content data}

Different statistical analyses were carried out for the whole database of gravimetric moisture content data, in order to exclude outliers. These methods were: within \pm 1.5 interquartile (IRQ) range, $\pm 3 \sigma$ range, Grubbs-test (Grubbs, 1969) and Dixon's Q test (Dean and Dixon, 1951). Evaluating the results of each statistical method, within \pm 1.5 interquartile (IRQ) range was used.

The method applying IRQ data filter, described by Baráth et al. (1996), defines the first and the third quartiles (Q1, Q3). Between the two values, interquartile range was calculated. Extreme values are determined as values which are too high or too low compared to the other values of the neighboring data. Six faulty samples were removed from data analysis due to erroneous sampling. The rest of the data falling into the interquartile range were acceptable, hence out of the 144 samples 121 remained.

\section{Data comparison}

Following the measurements and filtering the outlier's, correlation between the datasets were evaluated. Data from the $E C_{\mathrm{a}}$ measurement points in a 2, 3, 4, 5, 6, 7, 8, 9, 10, 15, 20, 30 and $40 \mathrm{~m}$ radius were collated. Average from the datasets was calculated respectively and compared to the average of the filtered gravimetric and volumetric moisture content data. Coefficients of determination were also calculated.

\section{Preparation of the datasets for mapping}

After filtering the moisture content data, volumetric moisture content values were calculated. Comparing the calculated volumetric moisture content data and measured $E C_{\mathrm{a}}$ values, $E C_{\mathrm{a}}$ based moisture content values were determined by applying Eq. 
(4). Using the calculated moisture content values, inverse distance weighted interpolation method was applied to create moisture content map by ArcGIS/ArcMAP 10.0 software for the investigated part of the study field, as well as the whole field. The result pixel size was $1 \mathrm{~m}$. In order to investigate the sample area a border was created with a $5 \mathrm{~m}$ buffer.

\section{RESULTS AND DISCUSSION}

The applied filtering methods resulted in different ranges for determining outliers. In case of evaluating each sampling sites individually the different filtering methods either excluded or included outliers. For instance, $40.5 \%$ gravimetric moisture content data in the $0-50 \mathrm{~mm}$ depth in sampling site A07 is clearly incorrect (notable differences did not appear during sample collection); however $\pm 3 \sigma$ rule would include it as a reliable data. At the same time in case the raw data range was narrow (e.g. sampling site A09) \pm 1.5 IRQ rule excluded reliable data $(21.56,22.06,23.27 \%$, respectively), which based on our field experience we did not agree with (Table 1).

Because the filtering of the database at each individual locations was not reliable due to small number of samples $(n=6)$ the full dataset was filtered. In order to exclude all possible outliers \pm 1.5 interquartile (IRQ) rule was applied (Table 2), therefore this dataset was used for further calculations.

Table 1. Comparison of gravimetric soil moisture data for the filtered data range (sample sites A07 and A09). These two sites were the most extreme datasets for the individual locations. The highlighted columns (bold) show the unreliability of the different statistical results.

\begin{tabular}{cccccc}
\hline $\begin{array}{c}\text { Depth of sample } \\
(\text { A07) }(\mathbf{c m})\end{array}$ & $\begin{array}{c}\text { Raw (unfiltered) } \\
\text { data } \\
\text { MWC (\%) }\end{array}$ & $\begin{array}{c} \pm \mathbf{1 . 5} \text { IRQ range } \\
\text { MWC (\%) }\end{array}$ & $\begin{array}{c} \pm \mathbf{3} \boldsymbol{\sigma} \text { range } \\
\text { MWC (\%) }\end{array}$ & $\begin{array}{c}\text { Grubbs-probe } \\
\text { MWC (\%) }\end{array}$ & $\begin{array}{c}\text { Dixon-probe } \\
\text { MWC (\%) }\end{array}$ \\
\hline $0-5$ & 40.55 & - & $\mathbf{4 0 . 5 5}$ & - & - \\
$5-10$ & 23.61 & 23.61 & $\mathbf{2 3 . 6 1}$ & 23.61 & 23.61 \\
$10-15$ & 24.05 & 24.05 & $\mathbf{2 4 . 0 5}$ & 24.05 & 24.05 \\
$15-20$ & 24.01 & 24.01 & $\mathbf{2 4 . 0 1}$ & 24.01 & 24.01 \\
$20-25$ & 24.55 & 24.55 & $\mathbf{2 4 . 5 5}$ & 24.55 & 24.95 \\
$25-30$ & 24.95 & 24.95 & $\mathbf{2 4 . 9 5}$ & 24.95 & 22.12 \\
$($ A09) & & & & & 22.03 \\
$0-5$ & 22.12 & $\mathbf{2 2 . 1 2}$ & 22.12 & 22.03 & 22.06 \\
$5-10$ & 22.03 & $\mathbf{2 2 . 0 3}$ & 22.03 & 22.06 & 2.56 \\
$10-15$ & 22.06 & $\mathbf{2 2 . 0 6}$ & 22.06 & - & - \\
$15-20$ & 21.56 & - & 21.56 & 22.06 & - \\
$20-25$ & 22.06 & - & 22.06 & & - \\
$25-30$ & 23.27 & - & 23.27 & & \\
\hline
\end{tabular}

Table 2. Results of the statistical analysis on the full dataset of gravimetric soil moisture content data. For mapping the data \pm 1.5 (IRQ) rule filter was used due to the lowest standard deviation.

\begin{tabular}{lccccc}
\hline & $\begin{array}{c}\text { Raw data } \\
\text { GWC }(\%)\end{array}$ & $\begin{array}{c} \pm 1.5(\text { IRQ) } \\
\text { GWC }(\%)\end{array}$ & $\begin{array}{c} \pm 3 \sigma \text { range } \\
\text { GWC }(\%)\end{array}$ & $\begin{array}{c}\text { Grubbs-test } \\
\text { GWC }(\%)\end{array}$ & $\begin{array}{c}\text { Dixon's Q test } \\
\text { GWC (\%) }\end{array}$ \\
\hline Remaining samples & 144 & 121 & 144 & 135 & 135 \\
Minimum & 13.02 & 16.09 & 13.02 & 16.09 & 16.09 \\
Average & 21.63 & 21.30 & 21.63 & 21.36 & 21.39 \\
Standard deviation & 3.37 & 2.47 & 3.37 & 2.55 & 2.54 \\
Maximum & 40.55 & 26.88 & 40.55 & 26.99 & 26.99 \\
Q1 & 19.44 & 19.44 & 19.44 & 19.32 & 19.44 \\
Median & 21.10 & 21.02 & 21.10 & 21.08 & 21.09 \\
Q3 & 23.66 & 23.35 & 23.66 & 23.48 & 23.48 \\
\hline
\end{tabular}

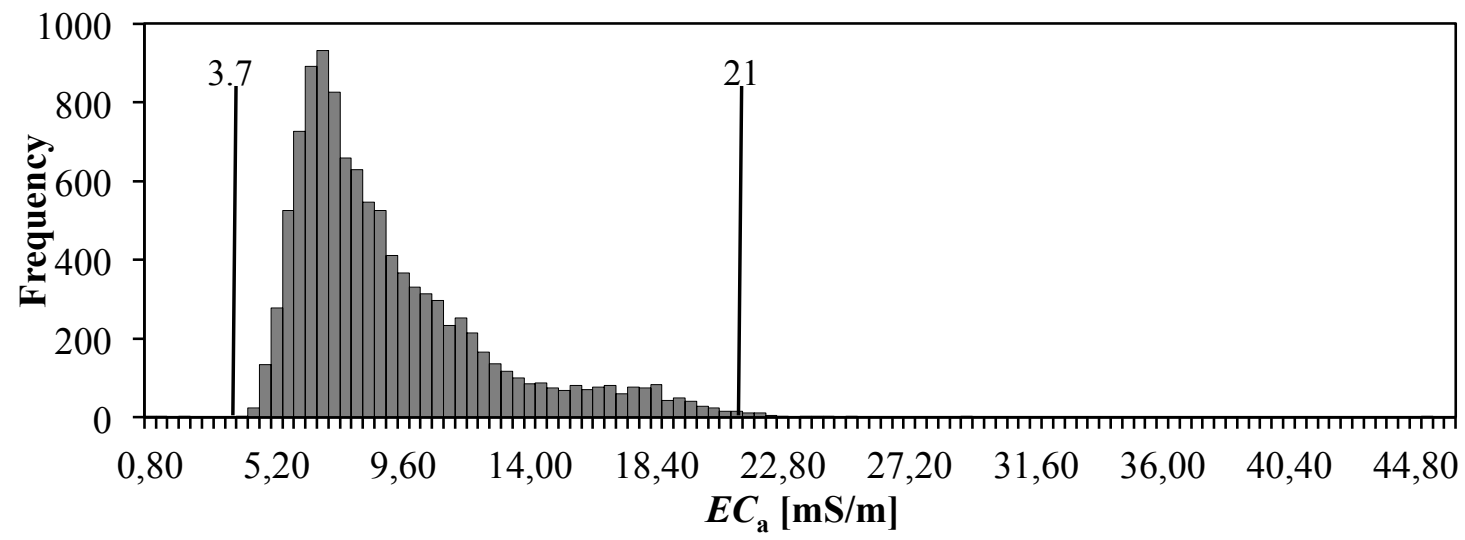

Fig. 4a. Frequency distribution of raw data of soil $E C_{\mathrm{a}}$ measurements with the indication of outlier borders. 


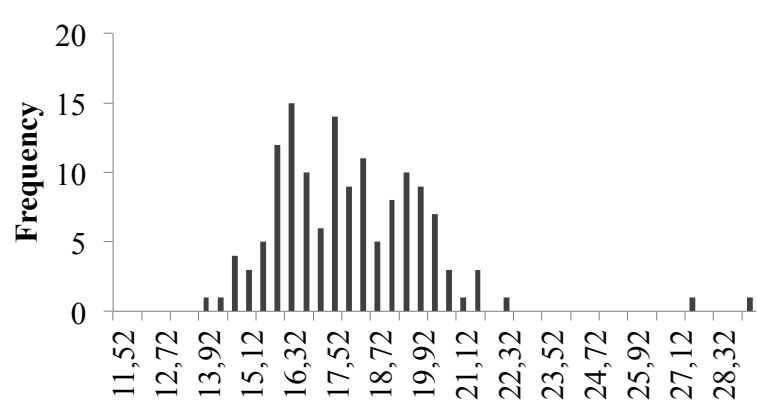

Gravimetric soil moisture content [\%]

Fig. 4b. Frequency distribution of gravimetrically measured soil moisture content data.

As shown on the histogram (Fig. 4a) $E C_{\text {a }}$ data is not distributed normally. The cause of this distribution is the variability of the soil appearing in the investigated field. This justified that log-normal statistics had to be applied for data filtering. The filtered dataset was used for creating statistically acceptable soil $E C_{\mathrm{a}}$ maps.

Moisture content data distribution after filtering can be considered as normal (Fig. 4b), therefore filtering does not require log-normal approach. Volumetric moisture content data was calculated from the measured and filtered gravimetric moisture content data for each location ( 25 sites).

Electrical conductivity values around the 25 sampling sites in 8 different radii were collected and averaged. Later these data were compared with the volumetric moisture content data. Empirical results showed strongest correlation in $5 \mathrm{~m}$ diameter, applying \pm 1.5 interquartile (IRQ) filtering (Table 3 ). However, there were only slight differences in the correlation values regardless of distance or applied filtering method. According to the data comparison results, we state that coefficient of determination for volumetric moisture content and measured $E C_{\mathrm{a}}$ is $\mathrm{R}^{2}=0.87$, which shows strong correlation between the two datasets. The equation for calculation of volumetric moisture content based on the $E C_{\mathrm{a}}$ measurements by applying adjusted Archie's law for the dataset shown in Fig. 5 was:

$\theta=\left(\frac{E C_{a}}{0.000471052}\right)^{\left(\frac{1}{3.458077394}\right)}$.

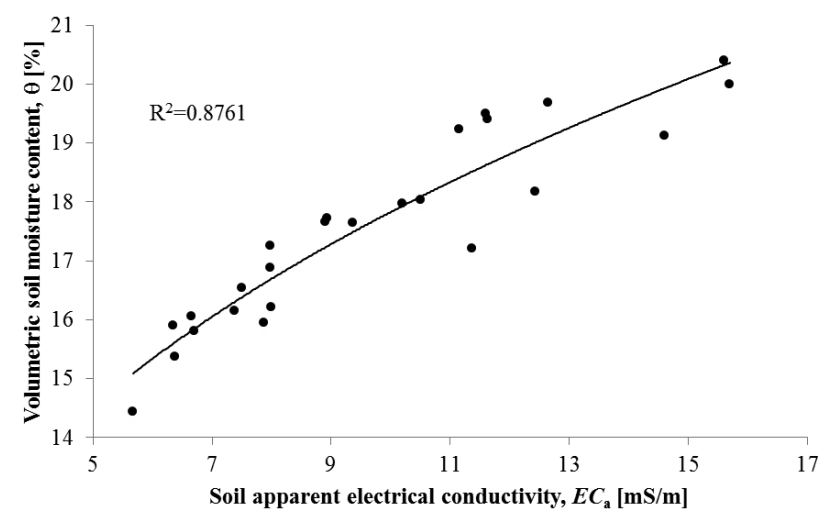

Fig. 5. Archie's equation based on relationship between volumetric soil moisture content $(\theta)$ and soil apparent electrical conductivity $\left(E C_{\mathrm{a}}\right)$ of the 25 reference sampling points.

Volumetric moisture content map based on gravimetric moisture content measurements (Fig. 6) showed high variability in the investigated field. Due to the interpolation, the values appearing on the map between the sampling locations are oversimplified. In order to create a more accurate map denser sampling or different measurement method has to be applied.

The soil electrical conductivity map provides reliable measured data for each $5 \mathrm{~m} \times 5 \mathrm{~m}$ area, therefore the $E C_{\mathrm{a}}$ distribution map for the investigated area and the whole field showed the appearing differences in better resolution (Fig. 7).

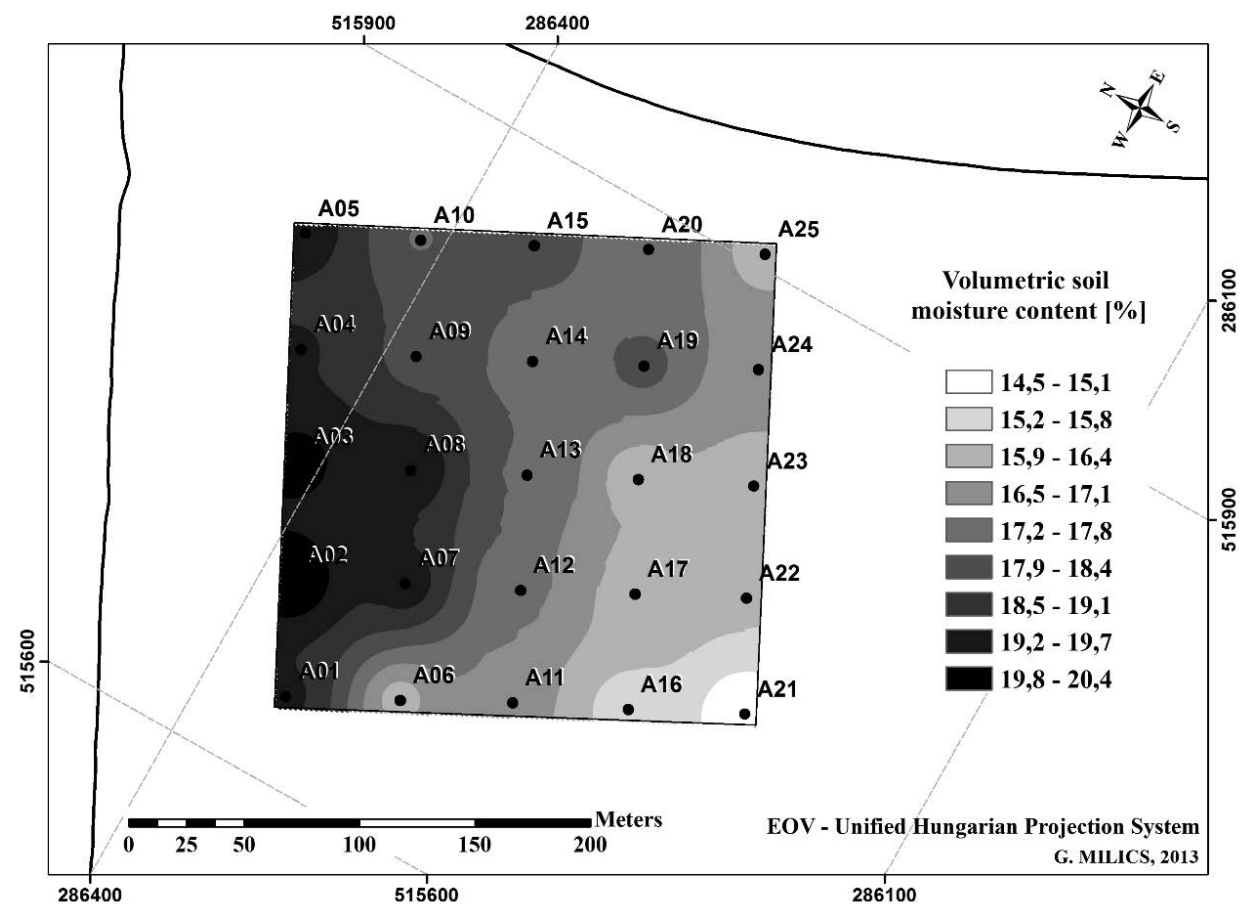

Fig. 6. Interpolated map based on the calculated volumetric soil moisture content data in the $0-0.3 \mathrm{~m}$ depth. 
Table 3. Coefficients of determination of filtering technique as a function of different search radius around the sampling locations. In all cases $5 \mathrm{~m}$ radius provided the highest correlations (in bold).

\begin{tabular}{lccccccccc}
\hline Distance $(\mathrm{m})$ & 2 & 3 & 4 & $\mathbf{5}$ & 6 & 7 & 8 & 9 & 10 \\
\hline Raw data & 0.645 & 0.740 & 0.736 & $\mathbf{0 . 7 4 7}$ & 0.735 & 0.736 & 0.728 & 0.707 & 0.709 \\
\pm 1.5 (IRQ) & 0.801 & 0.837 & 0.830 & $\mathbf{0 . 8 4 7}$ & 0.843 & 0.841 & 0.831 & 0.823 & 0.826 \\
$\pm 3 \sigma$ range & 0.780 & 0.823 & 0.818 & $\mathbf{0 . 8 4 0}$ & 0.836 & 0.831 & 0.825 & 0.819 & 0.822 \\
Grubbs-test & 0.801 & 0.837 & 0.829 & $\mathbf{0 . 8 4 5}$ & 0.842 & 0.841 & 0.833 & 0.823 & 0.827 \\
\hline
\end{tabular}

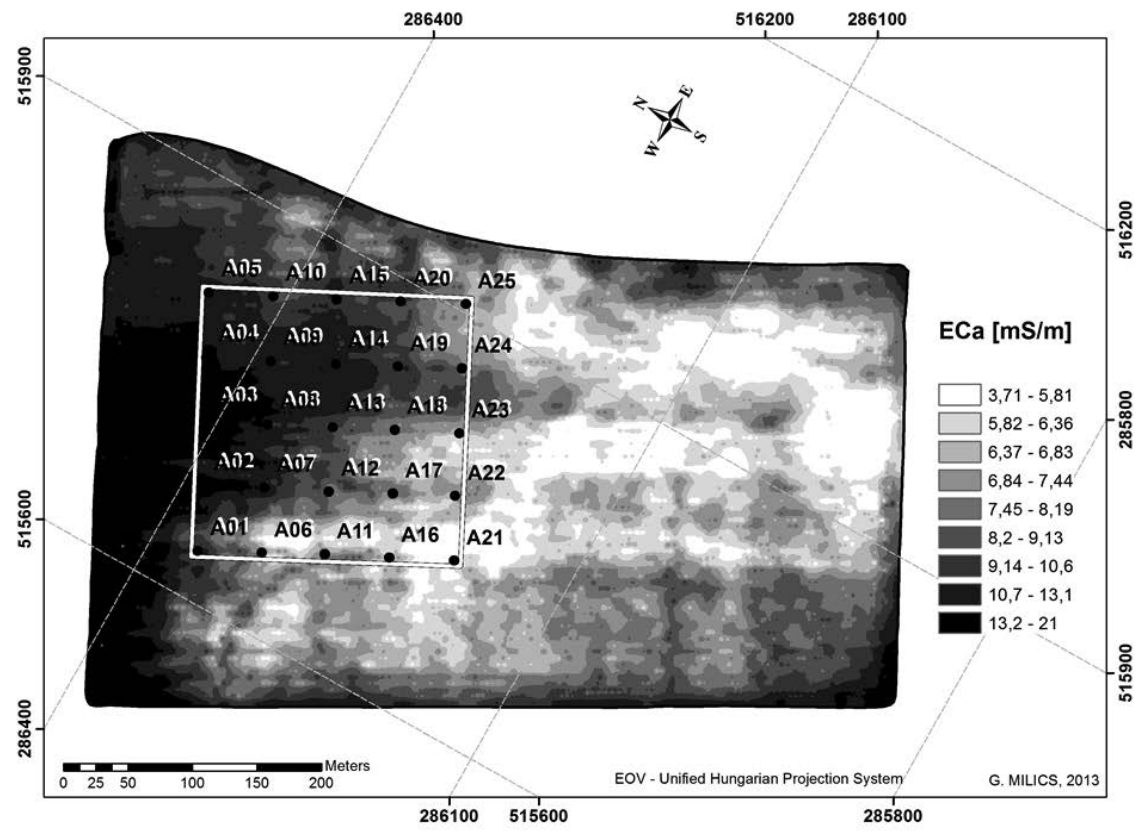

Fig. 7. Soil apparent electrical conductivity $\left(E C_{\mathrm{a}}\right)$ map in the $0-0.3 \mathrm{~m}$ depth. The rectangle frame shows the sampling area with the 25 sampling points.

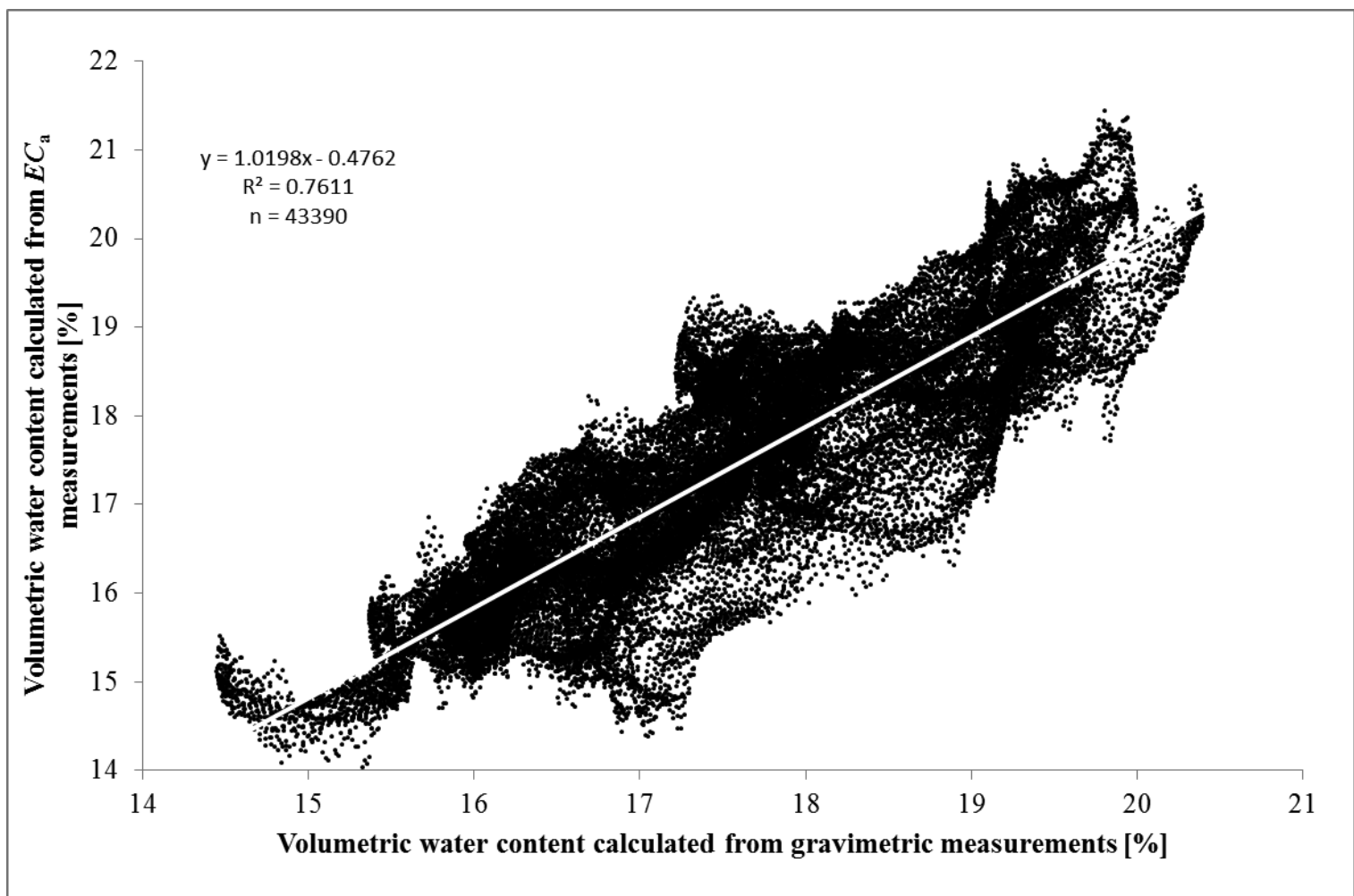

Fig. 8. Comparison of volumetric water content data based on calculation and interpolation of gravimetric samples vs. volumetric water content data calculated from $E C_{\mathrm{a}}$ measured values. 


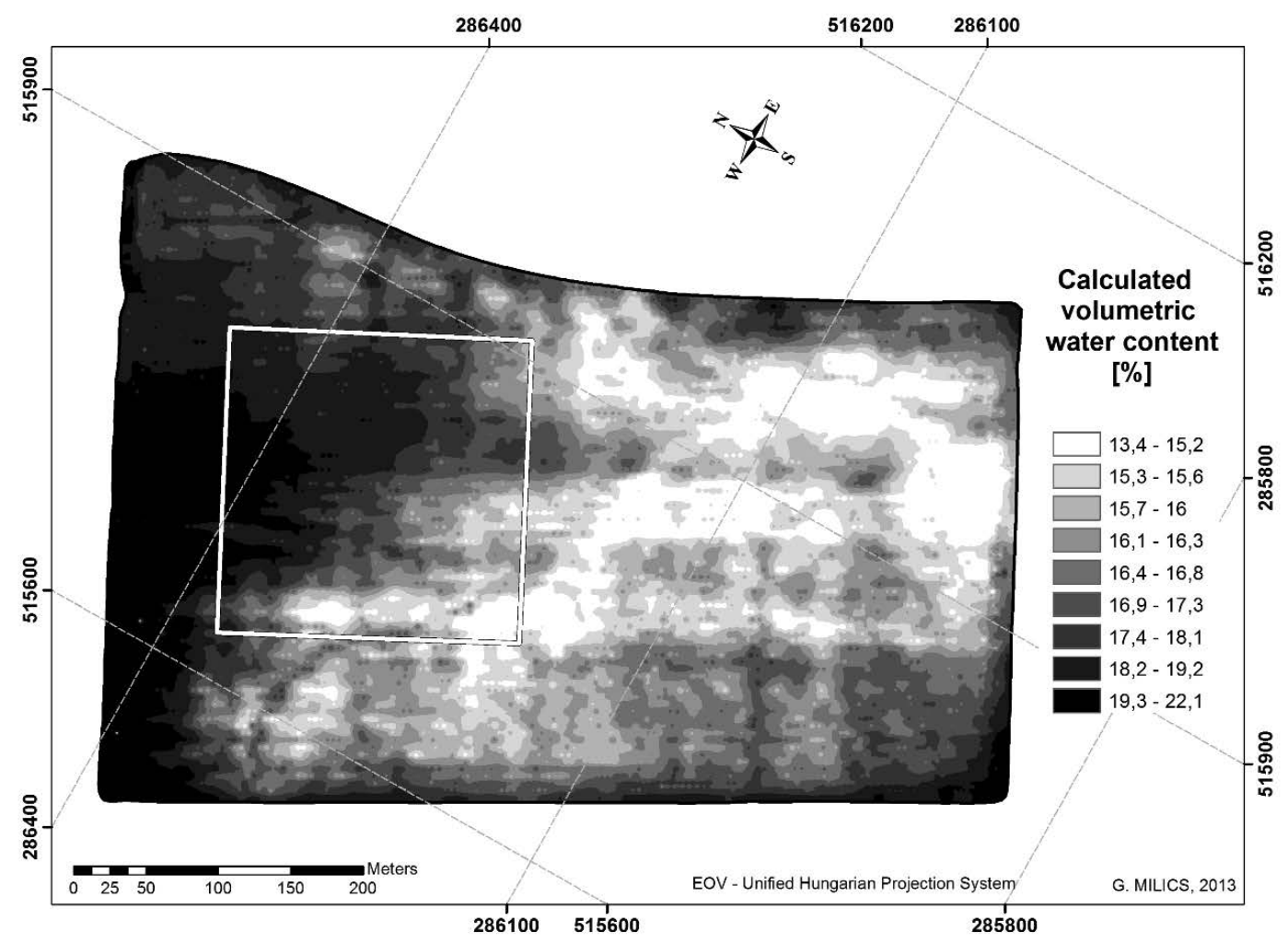

Fig. 9. Soil moisture content map in the investigated field. The map shows soil moisture content distribution for the whole field based on the 25 sampling point data comparison with $E C_{\mathrm{a}}$ measured values.

Datasets of the reference area containing the 25 sampling points were created by inverse distance weighting interpolation method and resulted in 43.390 data points. After investigating and comparing the two sets of values from the interpolated maps, a strong correlation was found between apparent electrical conductivity $\left(E C_{\mathrm{a}}\right)$ and moisture content data $\left(\mathrm{R}^{2}=0.76\right)$, however high scattering rate appears, caused by uncertainties on the interpolated map generated from manual sampling (Fig. 8).

Extending the $E C_{\mathrm{a}}$ based calculations for the full dataset (23.53 ha), volumetric moisture content map was created for the whole investigated field (Fig. 9). The pattern of the moisture content map shows differences in the field; therefore rational sampling strategy can be decided by the $E C_{\mathrm{a}}$ based measurements. With the help of the created map the number of sampling sites can be decreased, and the border of management zones can be decided with high accuracy.

\section{CONCLUSIONS}

We have found that for within-field moisture content mapping laborious manual sampling can be replaced with the online $E C_{\mathrm{a}}$ measuring method. Compared to manual sampling this method provides high sampling density resulting in more accurate soil moisture distribution map. The on-line measurement method is cost effective and applicable in the practice.

Veris-3100 electrical conductivity meter can be used for measuring differences appearing on a particular field. The measured apparent electrical conductivity values can be used to calculate moisture content of the soil in the investigated field. Besides, using maps made by geographical information systems, traditional statistical analyses also have verified strong correlations between the two data sets. Further research is needed to define how the relationship between moisture content and electrical conductivity changes depending on different soil types, clay content, and salinity of the soils.

We state that a moisture content map can be created from the continuous electrical conductivity values measured by the Veris-3100 in the investigated field. In broader sense we can assume that Veris-3100 device will be a useful tool to modify soil maps with different parameters such as moisture content, in a way that statistical averaging could be realistically modified.

Acknowledgements. The authors thank the Institute of Hydrology, Slovak Academy of Sciences, Institute of Crop Production of the Szent István University and the Hungarian Institute of Agricultural Engineering of the Ministry of Rural Development for providing equipment needed for the experiment and Ross Baxter for their help.

Furthermore, the authors thank for the support of TÁMOP4.2.2.A-11/1/KONV-2012-0013 and TÁMOP-4.2.2.B-10/12010-0018 "Talentum" research projects, VEGA 2/0083/11, APVV-0139-10, APVV-0271-07 and MAD SNK-5/2013.

\section{REFERENCES}

Anderson, T.W., Darling, D.A., 1954. A test of goodness of fit. Journal of the American Statistical Association, 49, 765769.

Baráth, C., Ittzés, A., Ugrósdy, G., 1996. Biometry. (Biometria.) Mezőgazda Kiadó, Budapest. (In Hungarian.)

Brevik, E.C., Fenton, T.E., 2002. The relative influence of soil water, clay, temperature, and carbonate minerals on soil electrical conductivity readings taken with an EM-38 along a 
Mollisol catena in central Iowa. Soil Survey Horizons, 43, 9-13.

Cook, P.G., Walker, G.R., Buselli, G., Potts, I., Dodds, A.R., 1992. The application of electromagnetic techniques to groundwater recharge investigations. Journal of Hydrology, 130, 201-229.

Corwin, D.L., Lesch, S.M., 2003. Application of soil electrical conductivity to precision agriculture. Theory, principles and guidelines. Agron. J., 95, 455-471.

Corwin, D.L., Lesch, S.M., 2005. Apparent electrical conductivity measurements in agriculture. Computers and Electronics in Agriculture, 46, 11-43.

Corwin, D.L., Rhoades, J.D., 1982. An improved technique for determining soil electrical conductivity-depth relations from above-ground electromagnetic measurements. Soil Sci. Soc. Am. J., 46, 517-520.

Corwin, D.L., Rhoades, J.D., 1984. Measurement of inverted electrical conductivity profiles using electromagnetic induction. Soil Sci. Soc. Am. J., 48, 288-291.

Dean, R.B., Dixon, W.J., 1951. Simplified statistics for small numbers of observations. Anal. Chem., 1951, 23(4), 636638 .

Doležal, F., Matula, S., Barradas, J.M.M., 2012. Improved horizontal installation of large soil moisture content sensors and interpretation of their readings in terms of preferential flow. J. Hydrol. Hydromech., 60, 2012, 4, 333-338.

Ellsbury, M.M., Woodson, W.D., Malo, D.D., Clay, D.E., Carlson, C.G., Clay, S.A., 1999. Spatial variability in corn rootworm distribution in relation to spatially variable soil factors and crop condition. In: Robert, P.C., Rust, R.H., Larson,W.E. (Eds.), Proceedings of the Fourth International Conference on Precision Agriculture, St. Paul, MN, 19-22 July 1998. ASA-CSSA-SSSA, Madison, WI, USA, 523533.

Fitterman, D.V., Stewart, M.T., 1986. Transient electromagnetic sounding for groundwater. Geophysics, 51, 995-1005.

Grubbs, F., 1969. Procedures for detecting outlying observations in samples. Technometrics, 11(1), 1-21.

Halvorson, A.D., Rhoades, J.D., 1976. Field mapping soil conductivity to delineate dryland seeps with four electrode techniques. Soil Sci. Soc. Am. J., 44, 571-575.

Justel, A., Peña, D., Zamar, R., 1997. A multivariate Kolmogorov-Smirnov test of goodness of fit. Statistics and Probability Letters, 35(3), 251-259.
Kaffka, S.R., Lesch, S.M., Bali, K.M., Corwin, D.L., 2005. Site-specific management in salt-affected sugar beet fields using electromagnetic induction. Comput. Electron. Agric., 46, 329-350.

Kravchenko, A.N., Bullock, D.G., 2000. Correlation of corn and soybean gain yield with topography and soil properties. Agron. J., 92, 75-83.

Milics, G., 2013. Mapping soil properties for precision agriculture. Növénytermelés, 62, Suppl., 405-408.

Milics, G., Balla, I., Deákvári, J., Jolánkai, M., Nagy, V., Stekauerová, V., Neményi, M., 2012. Soil moisture and soil electrical conductivity measurements in site - specific agriculture. Pollution and Water Resources Columbia University Seminar Series, XLI, 219-231.

Milne, B.T., 1991. Heterogeneity as a multiscale characteristic of landscapes. In: Kolasa, J., Pickett, S.T.A. (Eds.). Ecological heterogeneity. Ecological studies., 86, New York, NY., Springer-Verlag, 69-84.

Paraskevas, C., Georgiu, P., Ilias, A., Panoras, A., Babajimopoulos, C., 2012. Calibration equations for two capacitance water content probes. Int. Agrophys., 2012, 26, 285293.

Rhoades, J.D., Corwin, D.L., Lesch, S.M., 1999. Geospatial measurements of soil electrical conductivity to assess soil salinity and diffuse salt loading from irrigation. In: Corwin, D.L., Loague, K., Ellsworth, T.R. (Eds.), Assessment of non-point source pollution in the vadose zone. Geophysical Monograph 108, American Geophysical Union, Washington, DC, USA, 197-215.

Shah, P.H., Shingh, D.N., 2005. Generalized Archie's law for estimation of soil electrical conductivity. Journal of ASTM International, 2(5), 1-20.

Sharma, B.D., Kar, S., Sarkar, S., 1997. Calibration of a water uptake simulation model under varying soil moisture regime and nitrogen level for wheat crop. Agricultural and Forest Meteorology, 83(1-2), 135-146.

Williams, B.G., Hoey, D., 1987. The use of electromagnetic induction to detect the spatial variability of salt and clay contents of soils. Aust. J. Soil Res., 25, 21-27.

Received 21 March 2013

Accepted 3 October 2013 